\title{
Comprehensive Model for Learning
}

\author{
Norma Josefina Ontiveros Hernández ${ }^{1}$, Miguel Pérez Ramírez², \\ Jesús Ángel Peña Ramirez ${ }^{1}$, Sócrates Espinoza Salgado ${ }^{1}$, \\ Mario Humberto Tiburcio Zuñiga ${ }^{1}$ \\ ${ }^{1}$ Tecnológico Nacional de México/Instituto Tecnológico de Zacatepec, Mexico \\ ${ }^{2}$ Instituto Nacional de Electricidad y Energías Limpias, Mexico \\ norma.oh@itzacatepec.edu.mx, mperez@ineel.mx, \\ penita14@hotmail.com, socrates.es@itzacatepec.edu.mx, \\ mario.tz@itzacatepec.edu.mx
}

\begin{abstract}
In this paper we discuss about learning contexts and analyze different aspects or factors which intervene in specific learning processes, so that the learning goals can be achieved effectively. The personalized context and flexibility are characteristics own by personalized learning. However, this can be expensive and inaccessible in practice, but it is argued that technology could provide some support to this personalization of learning. Thus, a comprehensive model to learning is delineated here and some examples of dimension are detailed.
\end{abstract}

Keywords: context of learning, learning process, multidimensional model, learning goals.

\section{$1 \quad$ Introduction}

The aim of this article is to analyze some of the characteristics or factors that are part of the learning context and that can determine the success or failure of the teachinglearning process.

The learning process includes three stages [1] where the student: 1) receives the information, 2) processes it, assimilates or understands it and, 3) finally, is able to make use of that information or knowledge through its application within the specific field of the acquired knowledge.

The problem that occurs in many educational institutions is that not all students present the same level of achievement. This could be due to multiple factors, for example, their sociocultural conditions, lack of prior knowledge, deficiency in their capacity for analysis and synthesis, lack of interest, lack of attitude, etc.

Here we offer a brief analysis in which we first propose to analyze the learning context and then integrate the support of technology to try to emulate the flexibility and richness of personalized instruction. Here we are assuming that personalized instruction is efficient in the sense that an instructor, who tries to teach a student, detects the deficiencies and strengths of his student and uses a variety of resources to get the student to reach the predefined learning goals; what is not practical in a group instruction. 
The rest of the article is organized as follows: The multidimensional model of learning is shown below. Afterwards, a discussion section includes some reflections on the dimensions described. Finally, some conclusions are included, which is followed by a list of references.

\section{Towards a Multidimensional Learning Model}

\subsection{Learning Context}

Learning contexts (LC) are conceived as the sum of factors that intervene in a specific learning process. From this point of view and unlike traditional instruction, based on groups of students and instructors in a classroom and even in distance mode, which is usually considered incomplete and less efficient, here the integral model is followed, where it is assumed that the more dimensions or factors are integrated into a specific learning process, that is the more complete is a specific learning context, the more efficient the instruction is to achieve a specific learning goal. However, the fact that different factors are present in a learning context does not imply that they exist in a disorderly manner. The most obvious factors may be present simultaneously, for example: text, audio, images, etc., but some others (also expressed as dimensions afterwards) may have the flexibility of being introduced at will or on demand, so that they are present when they are required or when they are more opportune so that they can support the reach of some learning goal.

\subsection{Related Work: Discussion}

Some authors [2] criticize the traditional methods of instruction of the cognitive domain based on textbooks and basic practical lessons, saying that they have several limitations to help students remember or recognize certain knowledge and develop their understanding, their intellectual abilities and his skills.

Intuitively, having a group of students, all of them with different abilities, we can see that the traditional instructional method will be appropriate for the skills of a subset of students in the group, but not for the rest of it. At most there will be some students who, to achieve the same advantage as those of the aforementioned subgroup, will cost them an extra effort, others could simply give up. Here we review the following two strands to learning.

\section{a) Theoretical approaches}

Different approaches and theories have emerged to improve learning. For example, some of the most representative are:

Behaviorism. It is a psychology strand proposed by John B. Watson (1878-1958) that defends the use of strictly experimental procedures to study observable behavior and denies any possibility of using subjective methods such as introspection. [3].

Constructivism. It is a position shared by different trends in psychological and educational research. Among them are the evolutionary theory of Piaget, which states 
that learning is a restructuring of cognitive structures, the student assimilates what he is learning under the prism of previous knowledge he has in his cognitive structures; the socio-cultural approach of Vygotsky, which affirms that learning is conditioned by the society in which we are born and develop, which implies the possibility of learning with the help of more skilled people; Ausubel's significant learning, which coincides with Piaget, that the starting point of all learning is knowledge and previous experiences and the most important factor that includes learning is what the student already knows and the current Cognitive Psychology, which they maintain that what is developed are fundamentally aspects related to basic cognitive processes, such as attention, memory and activities of storage and retrieval of information, as well as the amplitude of shortterm memory, executive strategies and metamemory or meta-knowledge [4]. And others could be included here, but from the intuitions mentioned above, it can be seen that the learning process requires a more integral approach, which could even include all these theories, so that instruction can have an impact on a larger audience.

One of the problems here is that usually, the instructional design is not directed to groups of students with the same skills, rather they are applied to a heterogeneous audience where each student has different abilities.

\section{b) Technology based approaches}

There is also the strand of technology. One of the most representatives are the Intelligent Tutoring Systems that based on interaction and progress of students tries to guide students in a "kind of" personalized instruction. Early version perhaps were not well-implemented [5], nonetheless the architecture is still a base to integrate other technologies. For instance, in [6] is presented an e-learning platform for automatic course personalization based on the Felder and Silverman pedagogical approach, based on the correspondence between teaching styles and learning styles. The platform is based on Diogene a LMS (Learning Management System) another technological tool. This source also introduces some formalism and ontologies in order to deal with course personalization. Again, on the course personalization, [7] proposes a learner profile design model to facilitate the development of personalized e-learning systems. They use the learner profile design models proposed by IEEE PAPI [8], and proposed an agent-based E-learning system architecture in order to achieve personalization. However, it is not automatic, for instance, it is the user who creates a user profile capturing all his personal information including preference, actions, goals etc. on the other hand agent is in charge of dynamically discover learning objects that fits a user's learning requirements. On the same lines [9] presents a review of user's models and user's modeling approaches for adaptive web systems. Despite focusing adaptation for web systems, it also touches learning topic such as learning styles, affective states, work contexts, domain models and of course ITS, features shared with learning contexts. After an exhaustive review they conclude that "... adaptive educational systems rely mostly on user knowledge and learning goals capitalizing on the modeling and representation techniques established in the field of ITS." There are also integral approaches, for example, Chen et al. [10] propose a theoretical framework based on integrative goals and some multimedia principles.

Here the integrative learning goals for instructional design [11] are based on the idea that the design begins with the identification of learning goals (eg, preparing a cake, 
which may include sub processes such as preparing the mix that includes the exact amount of all the ingredients, preheat the oven, bake it, decorate it, etc.). Sometimes, the goals are conceived as objectives that must reflect a certain human performance and sometimes as the capacities that must be acquired to reach a certain performance, in such a way that the goals have to do with a combination of several individual objectives that have to be integrated in a learning goal in such a way that the goals have to do with a combination of several individual objectives that have to be integrated into a learning goal.

\subsection{Multidimensional Approach to Learning}

The methodology we propose is not complicated. The integral term is not only adopted through the integrative goals, but we believe it is necessary to enrich the learning context through the integration of different factors that can connect instructors and students to achieve the learning goals effectively.

The main idea is that instructors have in mind or are aware that they can or perhaps should, resort and make use of different resources that support them so that the teaching-learning process is effective even when their audience is a heterogeneous group.

Thus, the intuition behind the multidimensional approach, proposes the consideration of as many factors as possible within each specific learning context, with the aim of providing stimulus to the greatest possible number of elements within the instructor's audience. As an example of these factors, we can mention the teaching techniques, the student's state of mind, the learning channels, etc. On the other hand, it is not only about integrating as many factors as possible, but about having the flexibility to apply the necessary factors in the appropriate context and time.

It is worth mentioning that apart from the pedagogical techniques and methodologies that the instructor can use, he could also resort, if possible, to the arsenal of tools that the technology provides him. For example: Learning Management Systems (LMS), elearning tools, virtual reality, intelligent tutors, etc.

In order to respond to the needs expressed is that we adhere to the multidimensional model of Learning [12].

\subsection{Model for the Multidimensional Approach to Learning}

Following the integral approaches and the use of technology, in relation to instruction, there are a variety of dimensions or factors that intervene in the learning process (Fig. 1) and that should be considered, if we want to achieve the main goal that is the transfer of knowledge. These dimensions may vary according to different situations, some examples are mentioned here.

- Student-Instructor Dimensions: According to the people involved, two dimensions can be identified that must intervene collaboratively to achieve the goal of knowledge transfer. In the case of students, this goal is to accommodate a new piece of information or a new organization of information, within their repository of knowledge in their brains. When this is done, the student could modify their behavior or points of view, increase their skills, etc. For instructors, this goal should be to teach and have evidence 
that knowledge has actually been transferred to the students' brains. These sub-goals involve dimensions that are perhaps simply assumed, but decisive, in order to achieve a combined effort to achieve the learning goal, that is, learners must really want to learn and instructors must really want to teach.

- Dimension of the Instructional Model: The instructional model is another dimension, different models have been proposed (e.g., behaviorism, constructivism, active learning, etc.), each with strengths and weaknesses. All of them provide some truth and some approach to improve learning (example, instructor-centered learning, studentcentered learning, learning focused on the interaction among instructors and students, etc.). There may be cases in which a model is used so effectively, that even students without interest are involved and guided towards a specific learning goal, however, depending on the domain, a model or combination of models must be selected in order to make efficient the instruction.

- Dimension of the instructional domain: This is another dimension; it is not the same football training, which includes mainly a physical activity that physics lessons, which could be mainly theoretical. It is clear that each domain demands specific skills from the learners, but it also determines which instructional method may be best to achieve an instructional goal.

- Dimension of the learning channels: One more dimension is given by the different types of students, according to the learning channels they prefer to use when they are learning, or that makes learning easier. Usually three types of apprentices are identified, according to their dominant learning channel, these are: auditory, those who learn best by listening; visual, those who learn best through visualization and kinesthetic for those who learn best by manipulating objects. Students also have different moods, different skills, etc., which, in combination with the learning channels, intervene in the efficiency of learning. We do not use just one learning channel, most people learn better by using more than one channel simultaneously. If the instructional design and content includes stimulus elements for these three learning channels, the efficiency will reach a larger audience.

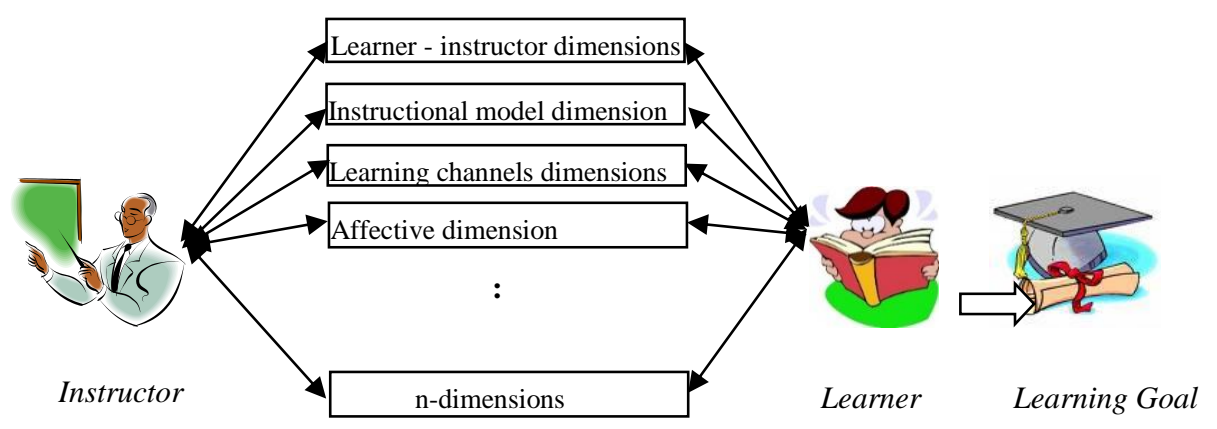

Fig. 1. Multidimensional model. Different dimensions intervene in the goal of knowledge transfer. 
- Affective dimension: Here we are assuming that the affective state of a student and his/her instructor could also determine whether the learning objective is satisfactorily achieved. As a simple example, a student might have argued with his girlfriend just before attending the lesson in the classroom. This could lead to an effective state, which results in a distraction and lack of concentration in the classroom. As another example, the exposure method used by the instructor could cause a state of apathy on the student or could motivate them to concentrate and effectively achieve the defined learning goals. Emotional states are inherent to students; therefore, the affective dimension should be an integral part of learning.

Other dimensions may be present in the learning process. Thus, a LC could be used to group the different dimensions involved in any learning process. A LC can include Personal Learning Contexts (PLC), which are subsets of dimensions associated with specific people, whether apprentices or instructors. We can also identify the Group Learning Contexts (GLC), which can be restricted to the sum of the PLCs of the trainees and instructors who participate in a specific learning process.

However, in the model proposed here, in the term Learning Context (LC), "context" is borrowed from the Natural Language Processing (PLN) community, where it is defined as a consistent set of propositions describing the set of beliefs of a person. Thus, unlike a learning environment that includes external elements that influence the learning process [13], a learning context is intended to be an internal personal view of an environment and thus a more accurate and complete view of the learning factors that influence such process, individually in each student, that is, where even external aspects really must be considered as each student perceives them and individualizes them within their learning process.

Integral approaches to learning are based on theories such as integrative goals. Thus, following these approaches, identifying, integrating and considering LCs within the learning process would provide a more complete and efficient tool to achieve knowledge transference.

\section{Discussion}

Here are some reflections on the dimensions described above. These are described by means of examples since it is not a generic recipe, each particular LC imposes its own demands and conditions. The same applies to the dimensions described that are only examples since there will be many more factors that intervene in learning and that have not been included here but will appear in some LC.

- Among the dimensions that are decisive in a LC of the proposed model, are those that refer to the roles of the Student and the Instructor. For example, if you have a teacher without a vocation, with lack of commitment or ethics, etc., or on the other hand you have a student, lacking commitment, without ethics, or who does not have enough energy to learn, then, this dimension will not be fulfilled. There can be multiple reasons why some of the participants do not comply with the condition imposed here, in which the teachers must want to teach and the students must want to learn and therefore, the teaching-learning process cannot be carried out effectively. 
- Regarding the dimension of the Instructional Model. It is evident that the teacher must be aware of the diversity of models already proposed and apply them on demand, that is, just as the student must learn to learn, the teacher must learn to teach besides having mastery of his area of knowledge.

- The dimension of the instructional domain is related to the previous dimension, so that knowing different instructional models the teacher should select those that are appropriate according to the content of their subject.

- In the case of the dimension of the learning channels, if an instructor had the possibility of using the technology (e.g. RV), it would be ideal. However, it is more important that you are aware that your group is made up of students of different types and try to design, create and use instructional content that contains visual, auditory and kinesthetic resources, as far as possible, in order to stimulate these channels of their students.

- In the case of the affective dimension it could be very difficult for a teacher to determine the affective state of each one of his students in order to act accordingly and continue to promote their learning. However, you could use standard measures that do not affect your students negatively and emotionally. For example, promoting participation and avoiding at all costs mocking or ridiculing someone for wrong answers or obvious questions. Other examples could be to promote respect in class, celebrate success and even errors to focus on as areas of opportunity.

On the other hand, technology has proven to be useful as a learning tool, since it has contributed to providing tools such as learning objects and repositories, learning management systems (LMS), content management systems (CMS), Intelligent Tutoring Systems (ITS) and Virtual Reality (VR) for training, among others. In addition, there is a key point in the use of technology in comprehensive approaches allows us to integrate different dimensions involved in the learning process, therefore provides the tools to increase the efficiency of the process.

The multidimensional model of Learning partially has been implemented is different Virtual Reality Training Systems. As an example, Virtual Reality allows recreating learning environments; where a user can also navigate and interact with the environment, providing different stimuli that turn it into a useful tool to integrate different aspects, such as those mentioned in the model for the creation of learning contexts, according to the proposed model (Fig. 1). For example, it is able to naturally support the dimension of learning channels.

A study conducted in 2009 [11] shows that we have almost the same preference for the three learning channels:

a) $37 \%$ of learning is tactile or kinesthetic, through the movement of things, touching and doing.

b) $29 \%$ of the learning is visual, through photos and images.

c) $34 \%$ of learning is auditory, through sounds and words.

However, it is known that while we learn we use more than one sensory channel. Within the literature of study strategies, this is known as multimodal study strategy and according to Fleming [14], the majority, approximately $60 \%$ of any population, falls 
into this category. Each learning style uses different parts of the brain, so the more channels are involved during learning, the more we remember what we learn [13].

Although in the literature of learning [14,15], different styles are mentioned such as reading/writing, logic, verbal, etc., here we focus on the primary sensory channels [10], whose percentages of preference were listed above. We believe that the importance of these learning channels lies in that they involve some of our basic senses. Here technologies such as Virtual Reality might be able to stimulate, to some degree, these learning channels and might include images, text, animations and audio.

It is worth mentioning here that the multidimensional model of Learning is rather a general model that in the near future might be formalized. Technology might provide the means to implement such model as is the case of both: a) the VR training systems already mentioned and that have proved to improve learning [16]; and b) research as the examples included in the section of related work.

The model presented explicitly demands some flexibility to introduce the described dimensions when these are required, this in accordance with personalized and adaptive instruction, technology can be of great help, at least partially, and it is the intelligent tutoring systems (ITS). The ITS could store information related to the student's progress in such a way that their strengths and weaknesses are registered, in order to know where the student needs support and to try to decide which dimensions would be the most adequate to support the student to reach the learning goals.

Thus far, there is not a comparative point for the products in a) and b), they are different and complementary and both fall under the multidimensional model approach to learning presented above.

\section{Conclusions}

Traditional methods of instruction can be considered incomplete, in the sense that they do not include different dimensions that intervene in specific learning processes. For example, in some Latin American countries there are educational institutions that evaluate the efficiency of the instructors, based on the percentage of graduated and failed students. This point of view is incomplete, since they do not consider some of the dimensions involved; For example, students may think that the learning process is only the responsibility of the instructors. This position seems to assign all the responsibility to the instructors, which is an incomplete criterion to evaluate the efficiency of learning and worse, could send the wrong message to some students and some educational authorities. Even the use of technology could provide incomplete methods.

Distance learning can be an alternative for problems of lack of access to education; however, if in a distance course the instructional content is only delivered to students along with some instruction to follow, and then some evaluations are applied, the student-instructor interaction may be reduced. It could be appropriate for people with autodidact orientation, but it leaves out other types of students.

On the other hand, the ideal learning context could be almost impossible, unless the instruction is personalized, in which case it could be less practical and surely expensive. We have to settle for including as many dimensions as possible in the learning process, 
but perhaps more important is to be aware of the different dimensions involved in specific learning processes successfully integrated in order to make effective the teaching-learning process.

\section{References}

1. Asim, S.: Exploring the Relationships among Learning Styles, Annotation Use and Reading Comprehension for Foreign Language Reading in a Hypermedia Environment. Thesis of Master of Arts in English Language Teaching Bogazi University (2003)

2. Chwen, J.C.: The design, development and evaluation of a virtual reality based learning environment. Australasian Journal of Educational Technology 22(1), pp. 39-63 (2006)

3. Tangient LLC. Teorías del aprendizaje: Conductismo. Wikispaces http://uocticgrupo6.wikispaces.com/Conduc-tismo. Consultada en Agosto 2016.

4. Tangient LLC. Teorías del aprendizaje: Constructivismo. Wikispaces http://uocticgrupo6.wikispaces.com/ Constructivismo. Consultada en Agosto 2016.

5. Ferster Bill. Intelligent Tutoring Systems: What Happened? E-learning industry. Instructional design. January 21, 2017. https://elearningindustry.com/intelligent-tutoringsystems-what-happened. Available on internet oct the 1st, 2018

6. Enver Sangineto. (2008). An Adaptive E-Learning Platform for Personalized Course Generation. In: Claus Pahl (ed) Architecture Solutions for E-Learning Systems. IGI Publishing (2008)

7. Wei, X., Yan, J.: Learner profile design for personalized eLearning systems. In: The International Conference on Computational Intelligence and Software Engineering (CiSE 2009), pp. 1-4 (2009)

8. IEEE. IEEE P1484.2/D7, 2000-11-28. Draft standard for learning technology. Public and private information (papi) for learners (papi learner)

9. Brusilovsky, P, Millán, E.: User models for adaptive hypermedia and adaptive educational systems. In: Brusilovsky, P., Kobsa, A., Nejdl, W. (eds.) The adaptive web: methods and strategies of web personalization, pp. 3-53. Springer-Verlag, Berlin, Heidelberg (2007)

10. Chen, C.J., Toh, S.C., Fauzy, W.M.: The Theoretical Framework for Designing Desktop Virtual Reality-Based Learning Environments. Journal of Interactive Learning Research 15(2), pp. 147-167 (2004)

11. Gagné, R.M., Merrill, M.D.: Integrative Goals for Instructional Design Chapter 5, pp. 127140 (1990)

12. Pérez-Ramirez, M., Ontiveros-Hernández, N.J.: Virtual reality as a comprehensive training tool. In: Proceedings of Workshop on Intelligent Learning Environments WILE, pp. 203215 (2009)

13. Advanogy. Discover your Learning Styles - Graphically! http://wwwlearning-stylesonline.com/.Site (August 2016)

14. Neil Fleming Teaching and Learning Styles VARK Strategies. Neil D Fleming. (2006)

15. Advanogy. Overview of Learning Styles http://www. learning-stylesonline.com/overview/.Site (August 2016)

16. Ayala-García, A., Galván-Bobadilla, I., Arroyo-Figueroa, G. et al.: Virtual reality training system for maintenance and operation of high-voltage overhead power lines. Virtual Reality 20(1), pp. 27-40 (2016) 